\title{
INVESTIGATIONS OF MASS TRANSFER IN ANNULAR GAS-LIQUID FLOW IN A MICROREACTOR
}

\author{
Paweł Sobieszuk*, Karolina Napieralska \\ Warsaw University of Technology, Faculty of Chemical and Process Engineering, Warynskiego1, \\ 00-645 Warsaw, Poland

\section{Dedicated to Prof. Ryszard Pohorecki on the occasion of his 80th birthday}

\begin{abstract}
The paper presents an investigation of mass transfer in gas-liquid annular flow in a microreactor. The microreactor had a meandered shape with a square cross-section of the channel $(292 \times 292 \mu \mathrm{m}$, hydraulic diameter $292 \mu \mathrm{m}$ ) and $250 \mathrm{~mm}$ in length. The rate of $\mathrm{CO}_{2}$ absorption from the $\mathrm{CO}_{2} / \mathrm{N}_{2}$ mixture in $\mathrm{NaOH}(0.1 \mathrm{M}, 0.2 \mathrm{M}, 0.7 \mathrm{M}, 1.0 \mathrm{M}$ and $1.5 \mathrm{M})$ water solutions was measured. Two velocities of gas flow and two velocities of liquid flow were used. In two cases a fully developed annular flow at the beginning of the channel was observed, whilst in two cases annular flow was formed only in about $2 / 3$ of the microchannel length. Based on the measurements of $\mathrm{CO}_{2}$ absorption rate, the values of volumetric liquid - side mass transfer coefficients with the chemical reaction were determined. Then physical values of coefficients were found. Obtained results were discussed and their values were compared with the values predicted by literature correlations.
\end{abstract}

Keywords: mass transfer, annular flow, microreactor

\section{INTRODUCTION}

Multiphase and homophase flows in microstructures play a significant role in many branches of contemporary technology. More and more frequently microreactors are used in producing a particular product, e.g. photochemical gas-liquid reactions (Ehrich et al., 2002), sulphonation and oxidation of hydrocarbons (Hessel et al., 2005), methane oxidation to formaldehyde (Zhang et al., 2011). Analytical methods (lab on a chip) constitute a great deal of microstructure usage (Churski et al., 2012), but also e.g. detection of gas solubility and diffusivity in liquids (Abolhasani et al., 2012; Sobieszuk and Pilarek, 2012). Due to the fact that high values of the interfacial area are observed in heterophase systems in microreactors with gas-liquid flow, they are widely examined as an innovative gas-liquid apparatus. There are a lot of published papers based of fundamental investigations of such a flow. In particular, it concerns hydrodynamics (Abadie et al., 2012; Pohorecki et al., 2008), pressure drop (Cygański et al., 2012; Saisorn and Wongwises, 2010), mixing (Commenge et al., 2006; Kolb et al., 2013; Malecha et al., 2009) and heat exchange (Hecht and Kraut, 2010). The greatest number of papers concerns mass transfer (Kashid et al., 2011; Sobieszuk et al., 2011; Yao et al., 2015). These investigations are conducted both for open and closed microchannels. In a closed channel in papers concerning hydrodynamics, all authors reported the presence of two main flow regimes, i.e. Taylor (slug) and annular ones. The Taylor flow is very stable and is present in a large range of media flow (Hessel et al., 2005). Therefore, it is the most interesting flow to carry out reactions in heterophase gasliquid and liquid - liquid systems. 
The annular flow is definitely a more rarely examined regime. It is a consequence of a short time of phase contact. However, such a stuation might be necessary and then the annular flow proves to be the appropriate one. A short time of the phase contact in the annular flow was used by Zhang et al. (2011) in investigating the kinetics of oxidation reaction of methane to formaldehyde. When enzymes were used in the liquid phase during the formation of slug flow, foaming was observed (preliminary experiments) making determination of the interfacial area impossible. During the creation of the annular flow, the foaming phenomenon was not observed; hence this regime might be dedicated to specific measurements of the rate of mass transfer in enzymatic reactions.

The present paper is focused on mass transfer in an annular flow, and more specifically, on determining the values of mass transfer coefficients. Furthermore, a microchannel of a meandered shape, and not the most typically described straight one, was used in experiments.

\section{EXPERIMENTAL SETUP}

The microreactor was made of glass and had a Y-shaped and meandered shape of its main channel. The cross-section of all the channels was square and hydraulic diameter was $0.292 \mathrm{~mm}$. The main channel length was $250 \mathrm{~mm}$. A scheme of meandered microreactor is shown in Fig 1a. A phase separator, in which liquid is separated from gas due to papillary rise, was applied. The separator scheme was presented in Fig $1 \mathrm{~b}$. The microreactor and the separator were fabricated by Mikroglas Chemtech GmbH from Mainz (Germany). The experimental set-up is shown in Fig. 2. The gases (nitrogen and carbon dioxide) were supplied from cylinders through reducing valves and gas flow regulators. Both gases were mixed before the inlet to the microchannel. Liquid was supplied by a syringe pump. The liquid flow was measured using a measuring cylinder and a stop watch. The two phase mixture leaving the microchannel was separated in a capillary separator. The outlet gas was directed to a gas chromatograph (Shimadzu GC-2014). The flow was recorded by a CMOS high speed camera (1200hs). The system allowed to record frames with the resolution of $1280 \times 1024$ pixels and the speed in the range from 500 to 4000 frames per second. The pixel size was about $10 \mu \mathrm{m}$. The microreactor was lit using a $500 \mathrm{~W}$ halogen lamp with a light diffuser. All the data were measured at room temperature. To eliminate possible channel heating, the halogen lamp was used only for several seconds. The rates of absorption of $\mathrm{CO}_{2}$ from a $\mathrm{CO}_{2} / \mathrm{N}_{2}$ mixture into an aqueous solution of $\mathrm{NaOH}(0.1 \mathrm{M}, 0.2 \mathrm{M}, 0.7 \mathrm{M}, 1.0$ $\mathrm{M}$ and $1.5 \mathrm{M})$ were measured. Two values of the gas flow $(6.0 \mathrm{ml} / \mathrm{min}, 6.5 \mathrm{ml} / \mathrm{min})$ and two values of the liquid flow $(0.12 \mathrm{ml} / \mathrm{min}, 0.17 \mathrm{ml} / \mathrm{min})$ were used. In all conditions the rate of absorption was measured twice: once for the entire microreactor, and for the second time using only the phase contactor and the separator, without the main gas - liquid microchannel. This method was used by Yue et al. (2007), and also in our earlier papers (Sobieszuk et al. (2008) or Sobieszuk et al. (2011)). The $\mathrm{CO}_{2}$ absorption rate was calculated from gas concentration changes between the inlet and the outlet compositions. The inlet gas concentration was about $38 \%$.

a)

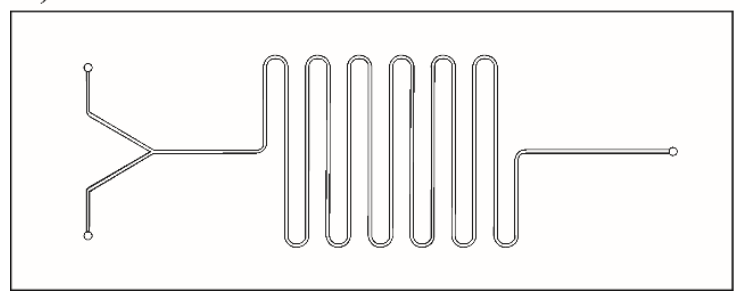

b)

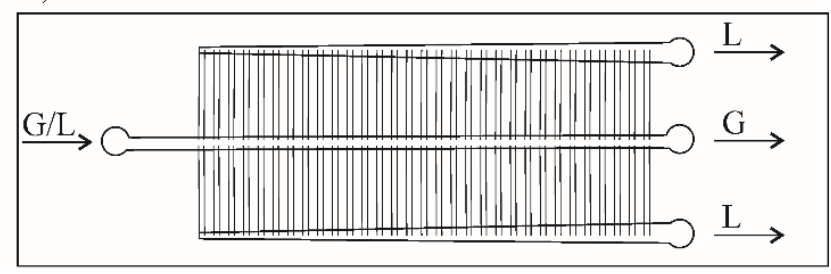

Fig. 1. Scheme of a) meandered microreactor, b) capillary phase separator 


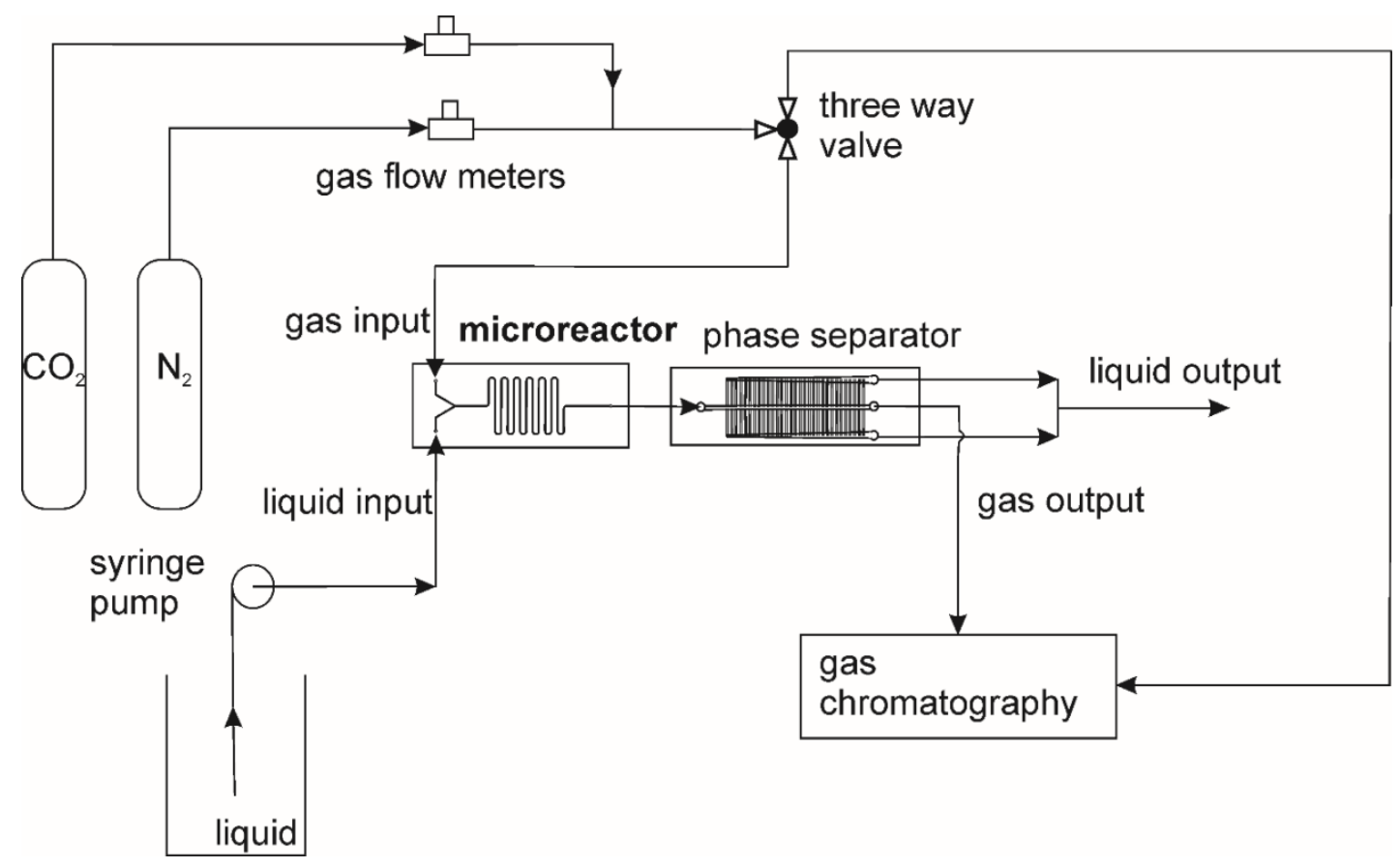

Fig. 2. Experimental set-up

\section{METHODOLOGY}

During the experiments the outlet $\mathrm{CO}_{2}$ concentration was measured for a constant volumetric gas and liquid flow values, a constant $\mathrm{CO}_{2}$ concentration at the gas inlet, and a constant $\mathrm{NaOH}$ concentration at the liquid inlet. Then the inlet $\left(p_{A 1}\right)$ and outlet $\left(p_{A 2}\right) \mathrm{CO}_{2}$ partial pressures were calculated. Finally, the rate of carbon dioxide absorption accompanied by a chemical reaction was found:

$$
N_{A}^{*}=\frac{Q_{G 1} p_{A 1}-Q_{G 2} p_{A 2}}{R T}
$$

Sobieszuk et al. (2014) report that for the Taylor flow in microchannels, gas side resistance of mass transfer (for $\mathrm{CO}_{2}$ ) can be neglected. Therefore, the partial pressure of $\mathrm{CO}_{2}$ at the gas inlet and outlet from the apparatus is equal to that at the interface at the inlet and outlet from the apparatus. Furthermore, the thermodynamic equilibrium described by the Henry's law was assumed at the interface:

$$
\begin{aligned}
& c_{A i 1}=H p_{A i 1}=H p_{A 1} \\
& c_{A i 2}=H p_{A i 2}=H p_{A 2}
\end{aligned}
$$

The absorption rate is defined by:

$$
N_{A}^{*}=k_{L}^{*} a c_{A i}^{A V} V
$$

and $c_{A i}^{A V}$ is the logarithmic average of gas concentration at the interfacial area:

$$
c_{A i}^{A V}=\frac{c_{A i 1}-c_{A i 2}}{\ln \frac{c_{A i 1}}{c_{A i 2}}}
$$

Consequently, from Eqs. (1) and (3) the experimental values of $k_{L}^{*} a$ can be estimated. 
In order to determine physical values of the coefficients, it was assumed that the reaction is infinitely fast, i.e. the condition is fulfilled:

$$
\frac{\sqrt{k_{2} c_{B 0} D_{A}}}{k_{L}}>>\frac{c_{B 0} D_{B}}{b c_{A i}^{A V} D_{A}}
$$

When the condition (5) is fulfilled, the enhancement factor is defined as follows:

$$
E=1+\frac{c_{B 0} D_{B}}{b c_{A i}^{A V} D_{A}}
$$

Since:

$$
E=\frac{k_{L}^{*} a}{k_{L} a}
$$

the values of the physical volumetric mass transfer coefficients were determined from Eq. (7). In order to verify the correctness of the assumption (5), $k_{L}$ values need to be known. Therefore, the interfacial area during annular flow was first estimated. The cross-section of the flow in the square microchannel is presented in Fig. 3 .

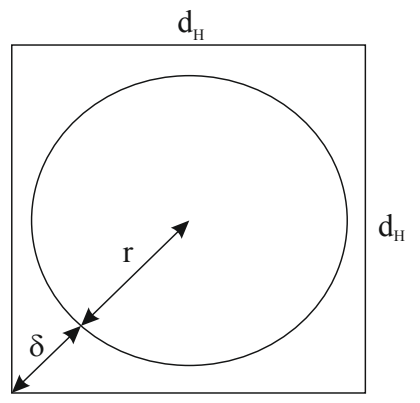

Fig. 3. Annular flow cross-section

Kreutzer et al. (2005) reported that in the rectangular channel, the thickness of the liquid film in microchannel corners can be determined from:

$$
\frac{\delta}{d_{H}}=0.35-0.25 \exp \left(-2.25 \mathrm{Ca}^{0.445}\right)
$$

Thus the gas stream is of the shape of a cylinder with the base radius equal to

$$
r=0.5 d_{H} \sqrt{2}-\delta
$$

Finally, the interfacial area was determined as:

$$
a=\frac{2 \pi r L}{V}
$$

where $L$ is the microchannel length. Using the $a$ value, the experimental values of $k_{L}$ were calculated and it was confirmed that the condition (5) was always fulfilled.

The obtained values of the physical mass transfer coefficients for the annular flow were compared with those resulting from the Higbie's model and a correlation formulated by Yue et al. (2007).

According to Higbie:

$$
k_{L}=2 \sqrt{\frac{D_{A}}{\pi \tau}}
$$


$\tau$ is the time of phase contact, which can be defined in the microreactor as:

$$
\tau=\frac{L}{u_{G}+u_{L}}
$$

Yue et al. (2007) investigated mass transfer in a straight microchannel of a rectangular cross section (1 $\mathrm{mm}$ in depth, $0.5 \mathrm{~mm}$ in width). They suggested the following correlation for the slug-annular and churn flow:

$$
\text { Sh } a d_{H}=0.058 \operatorname{Re}_{G}^{0.344} \operatorname{Re}_{L}^{0.912} S c^{0.5}
$$

The physicochemical properties of $\mathrm{CO}_{2}-\mathrm{H}_{2} \mathrm{O}-\mathrm{NaOH}$ system were widely published. From the available data the following were used:

- diffusivities $D_{A}$ and $D_{B}$ : Pohorecki and Moniuk (1988a), Danckwerts (1970),

- Henry's constant $H$ : Barret (1966),

- reaction rate constant $k_{2}$ : Pohorecki and Moniuk (1988b),

- viscosity of $\mathrm{NaOH}$ water solutions $\mu_{L}$ : Pohorecki and Moniuk (1991),

- density of $\mathrm{NaOH}$ water solutions $\rho_{L}$ : Pohorecki and Moniuk (1991).

\section{RESULTS AND DISCCUSION}

The investigation of absorption rate was carried out in the annular flow. It was determined that the fully developed flow regime was obtained at the gas flow rate of $6 \mathrm{ml} / \mathrm{min}$. The experiments were marked as series 1, and the photograph of this flow was presented in Fig. 4.

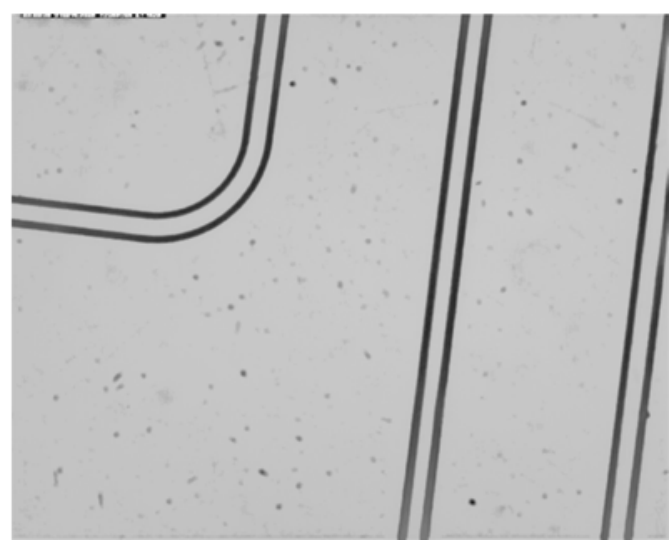

Fig. 4. Developed annular flow (series 1)

a)

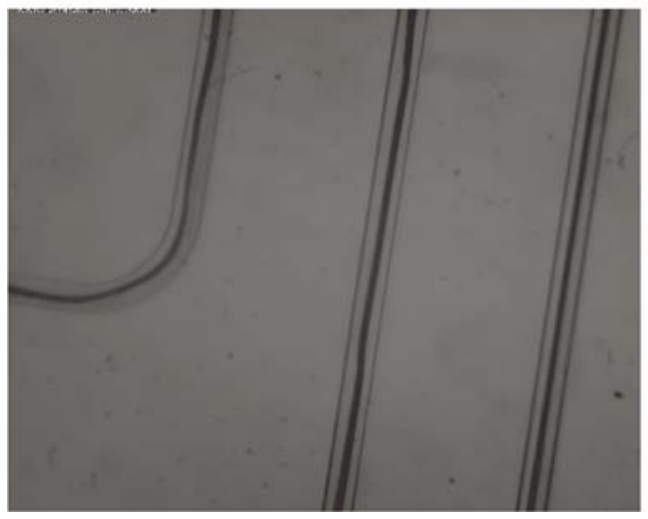

b)

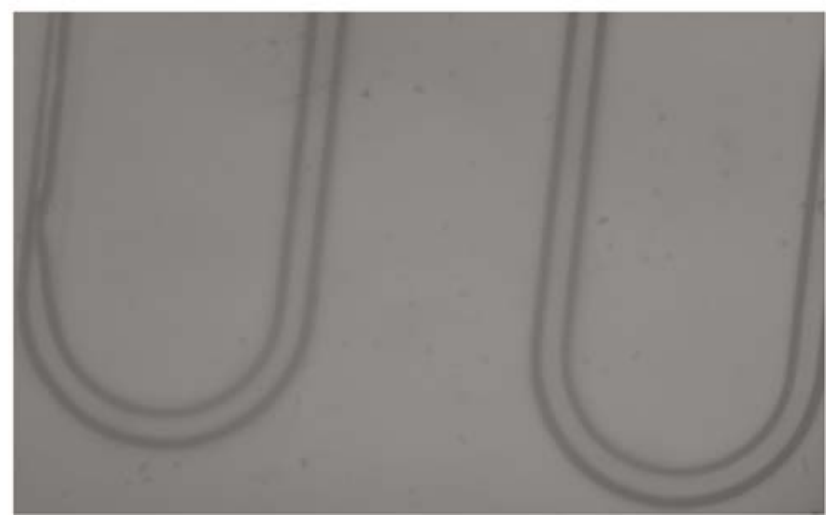

Fig. 5. Initially undeveloped annular flow a) and stability flow b) (series 2) 
For the gas flow rate equal to $6.5 \mathrm{ml} / \mathrm{min}$, the annular flow at the beginning of the microchannel was unstable (Fig. 5a); its stability was reached at about $1 / 3$ of microchannel length (Fig. 5b). The experiments were marked as series 2 .

The absorption rate was determined based on Eq. (1). A dependency of $\mathrm{CO}_{2}$ absorption rate in the function of superficial velocity of two-phase flow was presented in Fig. 6.

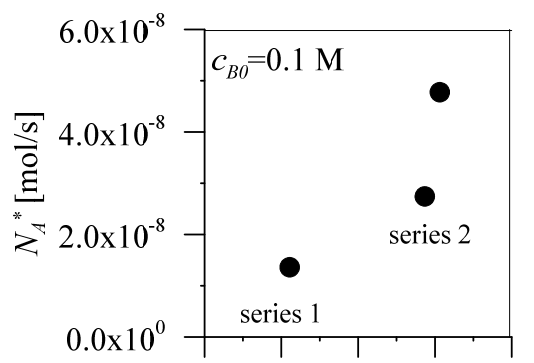

$\begin{array}{lllll}1.15 & 1.20 & 1.25 & 1.30 & 1.35\end{array}$

$u_{G}+u_{L}[\mathrm{~m} / \mathrm{s}]$
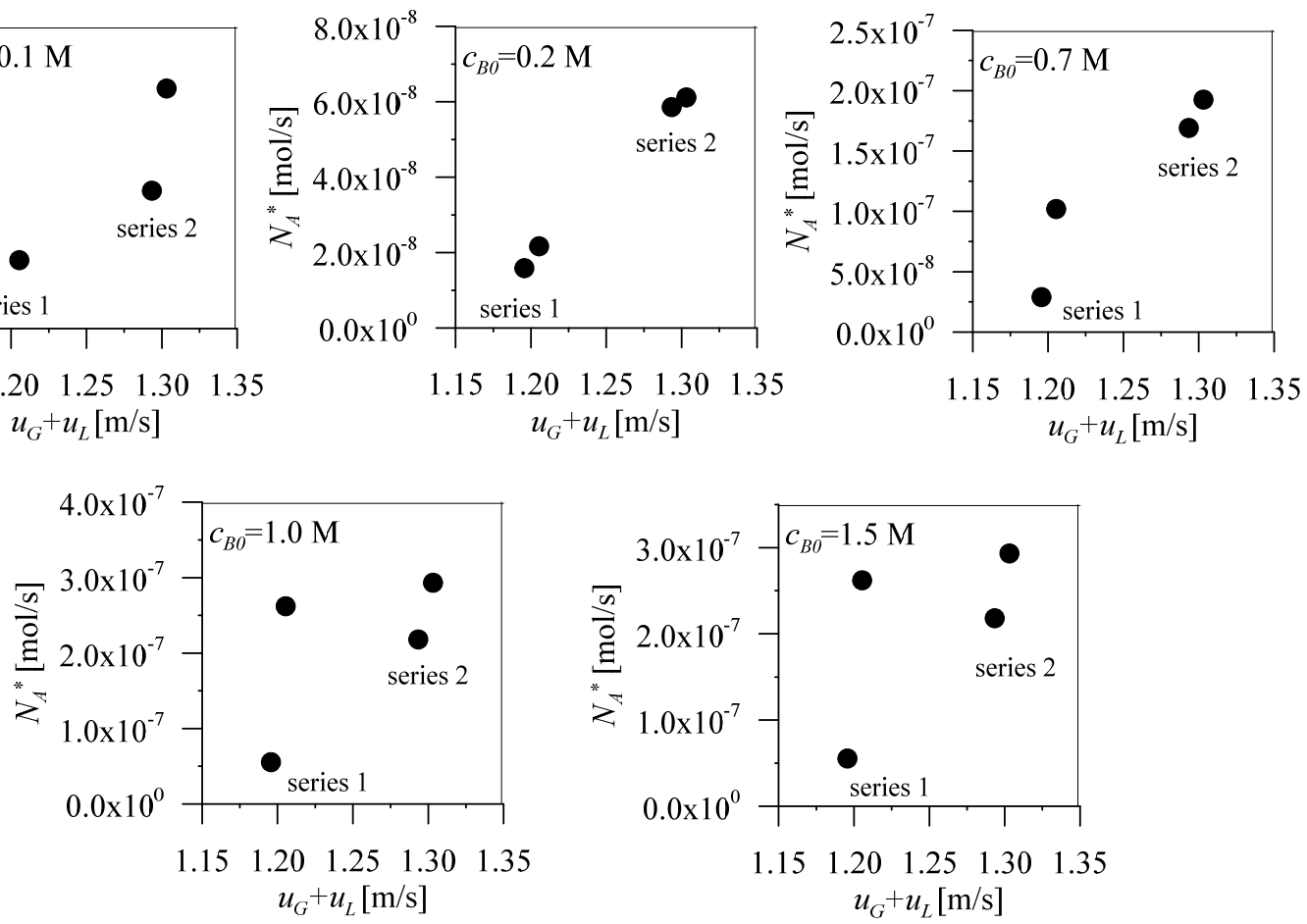

Fig. 6. Absorption rate in superficial velocity function of two-phase flow
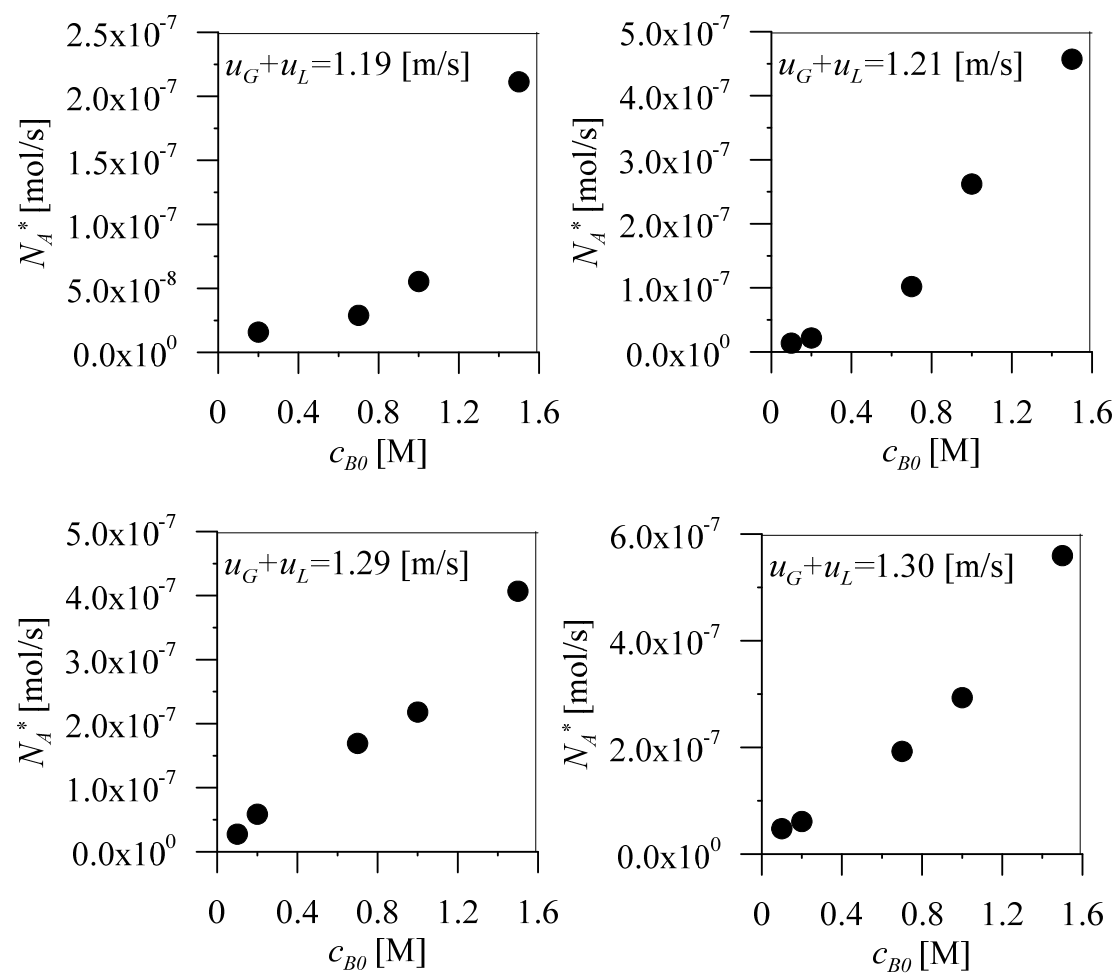

Fig. 7. $\mathrm{NaOH}$ concentration influence on the absorption rate 
As show in Fig. 6 the absorption rate increases with the increasing media flow. At the higher $\mathrm{NaOH}$ $(1.0 \mathrm{M}$ and $1.5 \mathrm{M})$ concentration, an insignificant decrease in the absorption rate for series 2 was observed. It occurred because during incompletely developed annular flow, the interfacial area decreased. In Fig. 7, NaOH concentration influence on the absorption rate in the same hydrodynamic conditions was presented. Here it was proven that the $\mathrm{NaOH}$ concentration increase results in the increase of the absorption rate.

Values of the volumetric mass transfer coefficients obtained from Eq. (7) are presented in Fig. 8a. As can be seen, $k_{L} a$ values are relatively insignificant in comparison with the values observed in the Taylor flow (Sobieszuk et al., 2008; Sobieszuk et al., 2011; Yue et al., 2007). Some differences in the $k_{L} a$ values at the same superficial two-phase flow velocity, can be observed. They may also result from different physicochemical properties of $\mathrm{NaOH}$ solutions. The concentrations of $\mathrm{NaOH}$ were changed in a wide range $(0.1-1.5 \mathrm{M})$.
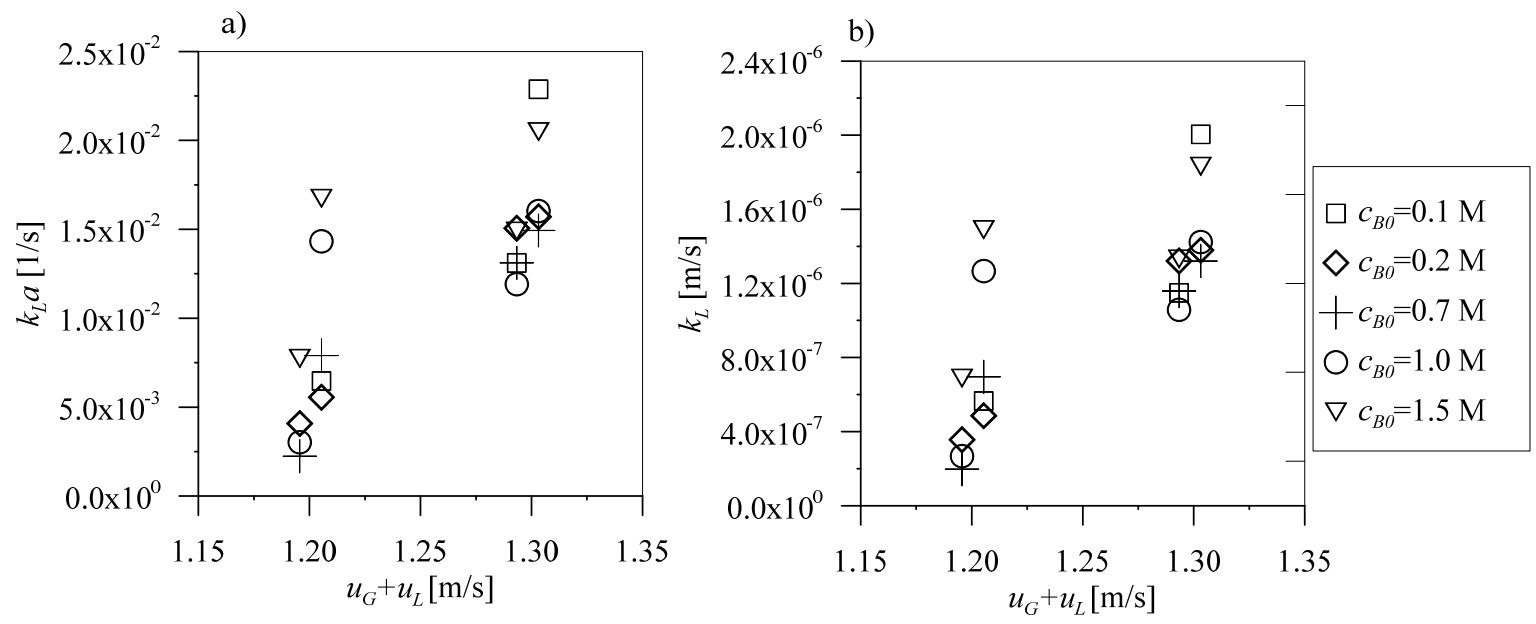

Fig. 8. $k_{L} a$ values a) and $k_{L}$ values b) in function of two - phase superficial velocity

Using the estimated values of the interfacial area (Eq. (10)) values of the physical liquid-side mass transfer coefficients were determined and it was established that the condition (5) was always fulfilled (it was checked for each $k_{L}$ experimental value), therefore the method is correct. Such an approach was used both for series 1 and series 2. The obtained values are presented in Fig. 8b.

A comparison of the obtained experimental values of $k_{L}$ with those predicted by the Higbie's model (Eq. (11)) and Yue et al. correlation (2007) (Eq. (13)) is presented in Fig. 9. Values of $k_{L}$ were averaged for the same $\mathrm{NaOH}$ concentration values.

Correlation (13) predicted values of $k_{L}$ close to experimental results. The differences result from the fact that Eq. (13) was suggested for the slug-annular or churn flows. Moreover, it was obtained in a straight microchannel. In the Higbie's model, the estimation of the phase contact time is the fundamental problem. In the flow in a closed microchannel its estimation is not simple since the phase contact is connected not so much with the media superficial velocity but rather with the real phase velocities. The phase velocity may significantly diverge from $u_{G}$ and $u_{L}$ values due to the great importance of surface interactions (surface tension, wettability). Similar differences in the use of Higbie's model during slug flow were obtained by Sobieszuk et al. (2011). It seems that the determination of the phase contact time is more obvious in an annular rather than in a slug flow, however, as seen in Fig. 9, the Higbie's model should not be used for predicting mass transfer coefficients in microchannels. 


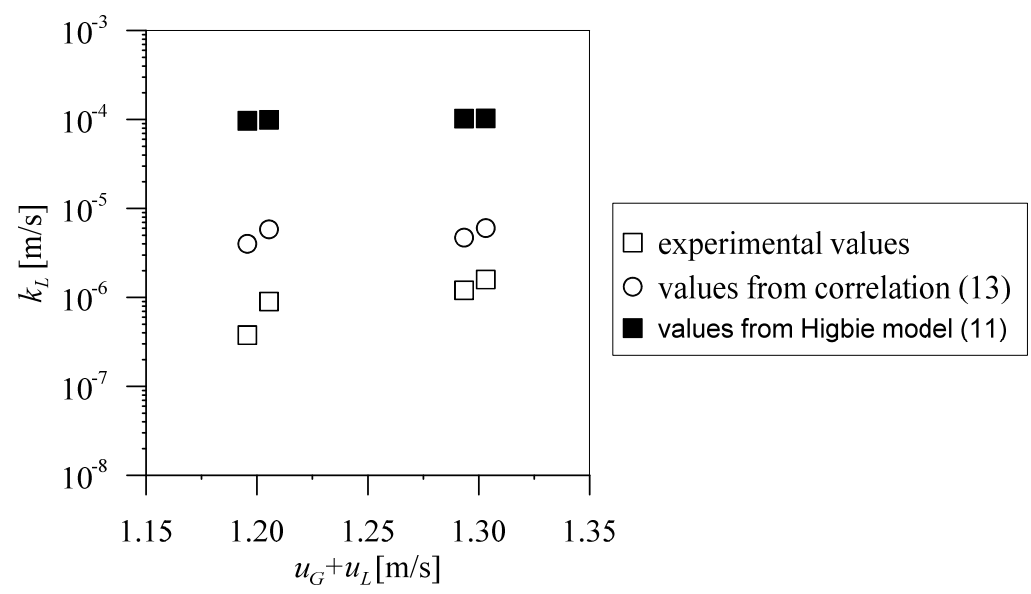

Fig. 9. The comparison of experimental $k_{L}$ values with values predicted by Higbie's model (11) and correlation (13)

\section{CONCLUSIONS}

There are few reports in the literature concerning mass transfer in the regime of annular flow in microreactors. The paper presented the investigation on $\mathrm{CO}_{2}$ absorption rate in $\mathrm{NaOH}$ aqueous solutions. The microreactor had a meandered shape with a square cross-section. The investigations were carried out in annular flow regime. Values of $k_{L} a$ and $k_{L}$ were determined. Interfacial area was determined using the correlation (8) for the liquid film thickness in a microchannel of a rectangular cross-section. The obtained results for the liquid-side mass transfer coefficients were compared with the values resulting from the Higbie's model and a correlation developed by Yue et al. (2007), the latter obtained in a straight microchannel in slug-annular and churn flows. Similar values of $k_{L}$ coefficients to those predicted from Yue et al. (2007) correlation were established. The problem with correct determination of contact time between the phases proves that the Higbie's model, similarly to a slug flow, should not be used in an annular regime in microchannels either.

\section{SYMBOLS}

\section{$a$}

$b$

$\mathrm{Ca}$

$c_{A}$

$c_{B 0}$

$d_{H}$

$D_{A}$

$D_{B}$

E

$H$

$k_{L}$

$k_{L} a$

$k_{2}$

$L$

$N_{A}$

$p_{A}$

$Q$ interfacial area per unit volume, $\mathrm{m}^{2} / \mathrm{m}^{3}$

stoichiometric coefficient

capillary number, - $\left(C a=u_{T P} \mu_{L} / \sigma\right)$

concentration of $\mathrm{CO}_{2}$ in gas phase, $\mathrm{mol} / \mathrm{m}^{3}$

initial concentration of $\mathrm{NaOH}$ in liquid phase, $\mathrm{mol} / \mathrm{m}^{3}$

hydraulic diameter of microchannel, $\mathrm{m}$

diffusivity of $\mathrm{CO}_{2}$ in liquid phase, $\mathrm{m}^{2} / \mathrm{s}$

diffusivity of $\mathrm{OH}^{-}$in liquid phase, $\mathrm{m}^{2} / \mathrm{s}$

enhancement factor

Henry's constant, $\mathrm{mol} /\left(\mathrm{m}^{3} \cdot \mathrm{Pa}\right)$

liquid - side mass transfer coefficient, $\mathrm{m} / \mathrm{s}$

volumetric liquid - side mass transfer coefficient, $1 / \mathrm{s}$

rate constant of reaction $\mathrm{CO}_{2}$ with ions $\mathrm{OH}^{-}, \mathrm{m}^{3} /(\mathrm{mol} \cdot \mathrm{s})$

microchannel length, $\mathrm{m}$

absorption rate, $\mathrm{mol} / \mathrm{s}$

$\mathrm{CO}_{2}$ partial pressure, $\mathrm{Pa}$

flow rate, $\mathrm{m}^{3} / \mathrm{s}$ 


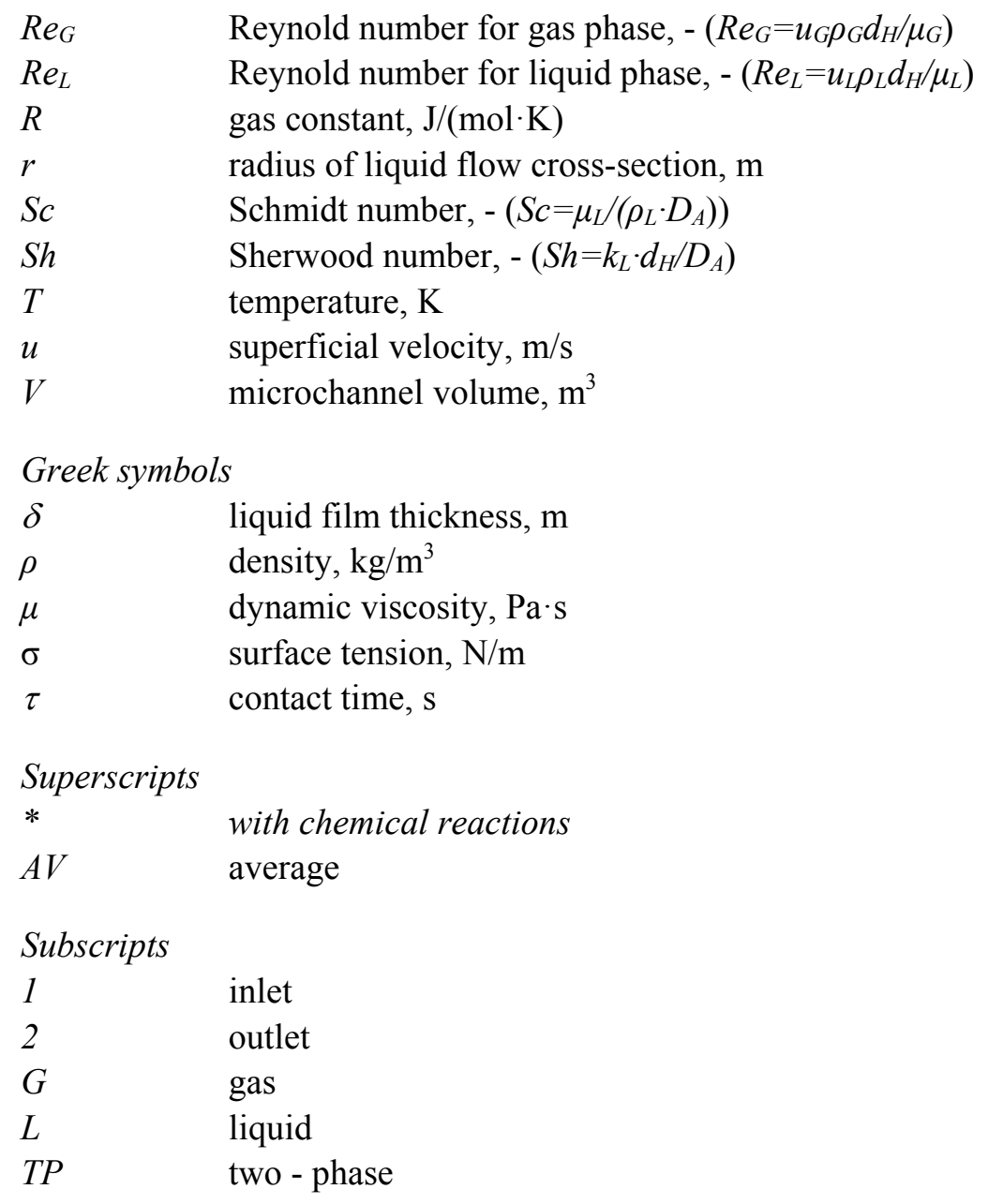

\section{REFERENCES}

AbadieT., Aubin J., Legendre D., Xuereb C., 2012. Hydrodynamics of gas-liquid Taylor flow in rectangular microchannels. Microfluid Nanofluid., 12, 355-369. DOI: 10.1007/s10404-011-0880-8.

Abolhasani M., Singh M., Kumacheva E., Günter A., 2012. Automated microfluidic platform for studies of carbon dioxide dissolution and solubility in physical solvents. Lab Chip, 12, 1611-1618. DOI: 10.1039/C2LC21043F.

Barret P.V.L., 1966. Gas absorption on a sieve plate. Ph.D. Thesis, University of Cambridge.

Churski K., Kamiński T.S., Jakiela S., Kamysz W., Barańska-Rybak W., Weibeld D.B., Garstecki P., 2012. Rapid screening of antibiotic toxicity in an automated microdroplet system. Lab Chip, 12, 1629-1637. DOI: 10.1039/C2LC21284F.

Commenge J.M., Obein T., Genin G., Framboisier X., Rode S., Schanen V., Pitiot P., Matlosz M., 2006. Gasphase residence time distribution in a falling-film microreactor. Chem. Eng. Sci., 61, 597-604. DOI: 10.1016/j.ces.2005.07.015.

Cygański P., Sobieszuk P., Pohorecki R., 2012. Pressure drop in two-phase gas-liquid (Taylor) flow. Chem. Proc. Eng., 33, 369-384. DOI: 10.2478/v10176-012-0033-y.

Danckwerts P.V., 1970. Gas-Liquid Reactions. Mc Graw-Hill, New York.

Ehrich H., Linke D., Morgenschweis K., Baerns M., Jahnish K., 2002. Application of microstructured reactor technology for the photochemical chlorination of alkylaromatics. Chimia, 56, 647-653. DOI: $10.2533 / 000942902777680063$.

Hecht K., Kraut M., 2010. Thermographic investigations of a microstructured thin film reactor for gas/liquid contacting. Ind. Eng. Chem. Res., 49, 10889-10896. DOI: 10.1021/ie1000431r.

Hessel V., Angeli P., Gavriilidis A., Lowe H., 2005. Gas-liquid and gas-liquid-solid microstructured reactors: Contacting principles and applications. Ind. Eng. Chem. Res., 44, 9750-9769. DOI: 10.1021/ie0503139. 
Kashid M.N., Renken A., Kiwi-Minsker L., 2011. Gas-liquid and liquid-liquid mass transfer in microstructured reactors. Chem. Eng. Sci., 66, 3876-3897. DOI: 10.1016/j.ces.2011.05.015.

Kolb A., Kraut M., Dittmeyer R., 2013. Kinetic investigation of the Dushman reaction at concentrations relevant to mixing studies in microstructures cyclone type mixers. Chem. Eng. Sci., 101, 454-460. DOI: 10.1016/j.ces2013.07.008.

Kreutzer M.T., Kapteijn F., Moulijn J.A., Heiszwolf J.J., 2005. Multiphase monolith reactors: Chemical reaction engineering of segmented flow in microchannels. Chem. Eng. Sci., 60, 5895-5916. DOI: 10.1016/j.ces.2005.03.022.

Malecha K., Golonka L.J., Bałdyga J., Jasińska M., Sobieszuk P., 2009. Serpentine microfluidic mixer made in LTCC. Sensors Actuators B, 143, 400-413. DOI: 10.1016/j.snb.2009.08.010.

Pohorecki, R., Moniuk, W., 1988a. Kinetics of reaction between carbon dioxide and hydroxyl ions in aqueous electrolyte solutions. Chem. Eng. Sci., 43, 1677-1684. DOI: 10.1016/0009-2509(88)85159-5.

Pohorecki R., W. Moniuk W., 1988b. Plate efficiency in the process of absorption with chemical reaction Experiments and example calculations. The Chem. Eng. J., 39, 37-46. DOI: 10.1016/0300-9467(88)80088-1.

Pohorecki R., Moniuk W., 1991. Viscosity and density of sodium and potassium alkaline solutions. Hung. J. Ind. Chem., 19, 175-178.

Pohorecki R., Sobieszuk P., Kula K., Moniuk W., Zieliński M., Cygański P., Gawiński P., 2008. Hydrodynamic regimes of gas-liquid flow in a microreactor channel. Chem. Eng. J., 2008, 135S, S185-S190. DOI: 10.1016/j.cej.2007.07.039.

Saisorn S., Wongwises S., 2010. The effects of channel diameter on flow pattern, void fraction and pressure drop of two-phase air-water flow in circular micro-channels. Exp. Therm. Fluid. Sci., 34, 454-462. DOI:10.1016/j.expthermflusci.2009.02.006.

Sobieszuk P., Cygański P., Pohorecki R., 2008. Volumetric mass transfer coefficient in a gas-liquid microreactor. Chem. Process Eng., 29, 651-661.

Sobieszuk P., Pilarek M., 2012. Absorption of $\mathrm{CO}_{2}$ into perfluorinated gas carrier in the Taylor gas- liquid flow in a microchannel system. Chem. Process Eng., 33, 595-602. DOI: 10.2478/v10176-012-0049-3.

Sobieszuk P., Pohorecki R., Cygański P., Grzelka J., 2011. Determination of the interfacial area and mass transfer coefficients in the Taylor gas-liquid flow in a microchannel. Chem. Eng. Sci., 66, 6048-6056. DOI: 10.1016/j.ces.2011.08.029.

Sobieszuk P., Ilnicki F., Pohorecki R., 2014. Contribution of liquid- and gas-side mass transfer coefficients to overall mass transfer coefficient in Taylor flow in a microreactor. Chem. Proc. Eng., 35, 35-45. DOI: 10.2478/cpe-2014-0003.

Yao C.Q., Dong Z.Y., Zhao Y.C., Chen G.W., 2015. Gas-liquid flow and mass transfer in a microchannel under elevated pressures. Chem. Eng. Sci., 123, 137-145. DOI: 10.1016/j.ces.2014.11.005.

Yue J., Chen G., Tuan Q., Luo L., Gonthier Y., 2007. Hydrodynamics and mass transfer characteristics in gasliquid flow through a rectangular microchannel. Chem. Eng. Sci., 62, 2096-2108. DOI: 10.1016/j.ces2006.12.057.

Zhang J., Burkle-Vitzthum V., Marquaire P.M., Wild G., Commenge J.M., 2011. Direct conversion of methane in formaldehyde at very short resistance time. Chem. Eng. Sci., 66, 6331-6340. DOI: 10.1016/j.ces2011.03.059.

Received 29 June 2015

Received in revised form 18 December 2015 Accepted 30 December 2015 